\section{The Rediscovery of Galligas}

TO THE EDITOR: Recently, Borges et al. published an interesting study about ventilation distribution in piglets comparing Technegas (Vita Medical Ltd.) and ${ }^{68} \mathrm{GaCl}_{3}$-labeled pseudogas ("Gallgas") (1), on which we would like to comment.

The last big milestone in the development of aerosols that can be used routinely for lung ventilation scintigraphy was the introduction of Technegas by Bill Burch, produced simply in the now-widelyspread Technegas generator $(2,3)$. After that, further labeling experiments with radionuclides other than ${ }^{99 \mathrm{~m}} \mathrm{Tc}$, in particular positron emitters such as ${ }^{68} \mathrm{Ga}$, were done in the 1990 s to study their behavior in the Technegas generator (4).

The global shortage of molybdenum and consequently ${ }^{99 \mathrm{~m}} \mathrm{Tc}$ in 2009 forced a reevaluation of the use of the ${ }^{68} \mathrm{Ga}$-labeled aerosol with the Technegas generator and PET/CT. We introduced it in human lung ventilation scintigraphy and called the aerosol Galligas (5). Subsequently, knowing that ${ }^{68} \mathrm{Ga}$-labeled microspheres have been recognized for more than $30 \mathrm{y}$ as a potential positron-emitting lung imaging agent $(6)$, we combined the ${ }^{68} \mathrm{Ga}$ ventilation scan with $a^{68} \mathrm{Ga}$-based perfusion scan for patients in whom pulmonary embolism was suspected (7).

Regionally disturbed ventilation is well characterized in Technegas images by hilar and tracheal activity depots and a lower peripheral deposition of the ventilation agent. In our series of 15 patients suspected of having pulmonary embolism, 5 showed regionally disturbed ventilation.

The higher efficacy of the dedicated PET ring detector system than planar $\gamma$-camera imaging or SPECT allows the application of low-activity ${ }^{68} \mathrm{Ga}$, resulting in an even lower radiation exposure than with ${ }^{99 \mathrm{~m}} \mathrm{Tc}$-labeled compounds (7). Furthermore, the shorter physical half-life of ${ }^{68} \mathrm{Ga}(68 \mathrm{~min})$ is sufficient for routine clinical use despite all the unexpected obstacles that can occur in the clinic, and both Galligas and ${ }^{68} \mathrm{Ga}$-microspheres can be prepared from the same generator elution.

We do know that other research groups have had the idea of vaporizing various radionuclides (including ${ }^{68} \mathrm{Ga}$ ) in the graphite boat of the Technegas generator (Ralf Bergmann, oral communication, February 2009; Hans-Jürgen Wester, oral communication, March 2011). However, to our knowledge, only our group has reported results (5).

\section{REFERENCES}

1. Borges JB, Velikyan I, Långström B, et al. Ventilation distribution studies comparing Technegas and "Gallgas" using ${ }^{68} \mathrm{GaCl}_{3}$ as the label. J Nucl Med. 2011;52:206-209.

2. Burch WM, Sullivan PJ, McLaren CJ. Technegas: a new ventilation agent for lung scanning. Nucl Med Commun. 1986;7:865-871.

3. Burch WM, Sullivan PJ, Lomas FE, et al. Lung ventilation studies with technetium-99m pseudogas. J Nucl Med. 1986;27:842-846.

4. Nozaki T, Muraoka H, Hara T, Suzuki T. Production of fine aerosols labelled with various radionuclides by sublimation from a graphite boat, and their properties and tracer use. Appl Radiat Isot. 1995;46:157-165.

5. Kotzerke J, Andreeff M, Wunderlich G. PET aerosol lung scintigraphy using Galligas. Eur J Nucl Med Mol Imaging. 2010;37:175-177.

6. Wagner SJ, Welch MJ. Gallium-68 labeling of albumin and albumin microspheres. J Nucl Med. 1979;20:428-433.
7. Kotzerke J, Andreeff M, Wunderlich G, Wiggermann P, Zöphel K. Ventilationperfusion lung scintigraphy using PET and ${ }^{68} \mathrm{Ga}$-labeled radiopharmaceuticals [in German]. Nuklearmedizin. 2010;49:203-208.

\author{
Jorg Kotzerke* \\ Klaus Zöphel \\ *Carl Gustav Carus Medical School \\ Fetscherstrasse 74 \\ D-01307 Dresden, Germany \\ E-mail: joerg.kotzerke@mailbox.tu-dresden.de
}

DOI: 10.2967/jnumed.111.089102

REPLY: We thank Drs. Kotzerke and Zöphel for their comments regarding our study (1) on ${ }^{68} \mathrm{GaCl}_{3}$-labeled pseudogas ("Gallgas") as a marker of ventilation distribution. We are sorry for not having included their correspondence (2) and report (3) on ${ }^{68} \mathrm{Ga}$ for assessing ventilation-perfusion distribution. Both were published after the submission of our manuscript, but an update by us should have revealed their letter from early 2010 . However, more important is the full agreement between us and Dr. Kotzerke and coworkers that ${ }^{68} \mathrm{Ga}$ can be a useful tracer for studying respiratory function. We also noticed that our studies complement each other. We have done animal experiments under more controlled conditions and have made comparisons with the present reference technique (Technegas), whereas Dr. Kotzerke and coworkers have studied patients with suspected pulmonary emboli, relating their findings to what historically is known as a typical pattern for pulmonary emboli.

We hope that our studies, taken together, will further the interest in using gallium tracers for respiratory function measurements, with the improvement in resolution over traditional technetiumlabeled markers and the $\gamma$-camera.

\section{REFERENCES}

1. Borges JB, Velikyan I, Långström B, et al. Ventilation distribution studies comparing Technegas and "Gallgas" using ${ }^{68} \mathrm{GaCl}_{3}$ as the label. J Nucl Med. 2011;52:206-209.

2. Kotzerke J, Andreeff M, Wunderlich G. PET aerosol lung scintigraphy using Galligas. Eur J Nucl Med Mol Imaging. 2010;37:175-177.

3. Kotzerke J, Andreeff M, Wunderlich G, Wiggermann P, Zöphel K. Ventilationperfusion lung scintigraphy using PET and ${ }^{68} \mathrm{Ga}$-labeled radiopharmaceuticals [in German]. Nuklearmedizin. 2010;49:203-208.

\section{Joao Batista Borges \\ Göran Hedenstierna* \\ *Clinical Physiology \\ Uppsala University Hospital \\ Uppsala 751 85, Sweden \\ E-mail: goran.hedenstierna@medsci.uu.se}

DOI: 10.2967/jnumed.111.089839

COPYRIGHT @ 2011 by the Society of Nuclear Medicine, Inc. 